\title{
Computational Fluid Dynamic Predictions on Effects of Screw Number on Performance of Single Blade Archimedes Screw Turbine
}

\author{
Muhammad Ilham Maulana ${ }^{1}$, Ahmad Syuhada ${ }^{2}$ and Fiqih Almas ${ }^{3}$ \\ ${ }^{1,2,3}$ Mechanical Engineering of Syiah Kuala University, Darussalam-Banda Aceh 23111, Indonesia
}

\begin{abstract}
One of the alternative solutions to reduce the impact of electricity crisis in Aceh and other isolated areas in Indonesia is by the construction of small-scale hydro power plants that can work efficiently on the heads lower than 10 meters. One suitable type of turbine applied to the head below 10 meters is the Archimedes screw turbine. Due to the lack of information about the application of low head power plants, resulting in applications of this type of turbine is still less in Indonesia. This paper examined the appropriate turbine model. Before experimental turbine testing, turbines were designed theoretically first and then analyzed numerically. The flow velocity and pressure patterns within the turbine were analyzed using ANSYS CFD (Computational Fluid Dynamic) software under design conditions for 7, 9 and 11 screw numbers for single blade turbine. Based on the results of pressure analysis, speed and turbulent kinetic energy, it found that turbine performance using 11 blades is better among the three turbines. However, the highest average speed was obtained on the turbine using 7 screws, which maximum pressure obtained on a turbine 7 screws of $1406 \mathrm{~Pa}$, on 9 screws on plane $1301 \mathrm{~Pa}$ and at 11 screws of $1175 \mathrm{~Pa}$. Based on the results of the analysis, it showed that the smaller the distance between the channel and turbine blades, the results were more efficient due to the absence of wasted streams. Therefore, the flow pressure in the inlet position all directly leaded to the tip off the blade to produce a momentum.
\end{abstract}

\section{Introduction}

Pico hydro scale power plant with a power of $5 \mathrm{~kW}-100$ $\mathrm{kW}$ is one of solving problems and is expected to provide a solution of the electrical energy crisis in remote areas that have not been powered by electricity. Its development typically utilizes the flow of water with a low head and a certain flow rate that is converted through the turbines rotate to the generator so that it becomes electrical energy. In Aceh region, there are many resources of water energy in the form of river currents, with an average height of falling water below 10 meters with a moderate current that can be utilized as energy generation. To utilize this energy, the suitable type of turbine used can work at a height of $<10$ meters i.e. Archimedes screw turbine [1].

Recent years there has seen several attempts to model various aspects of operation to obtain the specifications and dimensions of Archimedes screw turbines that are able to work optimally. Rorres (2000) lays out an analytical method to optimize design an Archimedes screw geometry for pumping applications and states that the optimum pitch ratio depends on the amount blade and radius ratio (R1 / R0) equal to 0.54 [2]. Based on the study conducted by Rorres, Muller created a simplified model for Archimedes screw turbine that idealizes the turbine's blades as moving weirs. He identified that the efficiency of Archimedean screws is a function of geometry and losses. He also showed that efficiency dependable with number of turns [3]. Guilhem Delinger et al (2016) also did experimental research of Archimedes screw turbine. They derived some formulas based on Rorres result. Their research shows both theoretical and experimental values of efficiency decrease when screw inclination increases [4]. Then, Lubitz proves that leakage and slope decrease will cause head differences between bucket declines as the amount of leak flow rate reduction is driven by pressure differentials. Thus, Archimedes screw efficiency will increase when the slope is set low (decrease) [5].

Some other studies have been done numerically to obtain an overview of the flow conditions of various turbine dimensions [6-8]. Stergiopoulou et al (2013) examines the hydrodynamic behavior of the Archimedes turbine, which aims to harness the hydraulic and technical potential of river currents and tidal currents [6]. Mutasim (2014) proves that flow pattern calculation results indicate the highest streamline velocity at the helical blade suction surface compared with the discharged surface. His study shows that the prediction

\footnotetext{
Corresponding author: ilhammaulana@unsyiah.ac.id
} 
of particle impact occurs mostly on the entering surface blade and along the leading edge of the screw runner [7].

Recently there have been studied on the effect of blade numbers on pressure behavior in the turbine using the standard model of k-epsilon turbulence. It states that turbines with different number of blades have obvious pressure drop at a quarter-length distance from the suction side of the blade inlet and single-blade turbine shows a more uniform distribution of pressure drop across all parts of the blade [8].

Therefore, the purpose of this paper is to obtain the optimal design of an Archimedes screw turbine through studied the effect of screw number on a single blade Archimedes turbine to pressure and turbine of kinetic energy using CFD. This optimization will be performed under the assumption that the length and the radius of the screw is specified, for clearly the effect of screw number to water lifted in each revolution. This research is mainly on the design, simulation, and flow characterization occurring within the Archimedes screw.

\section{Numerical Models}

The most important thing to be done in the computing process is the modeling of turbulent structures in the flow field. This turbulent structure occurs at various timescales and lengths, creating a model that can analyze all these possibilities is not easily practicable. There are different turbulence models available for turbulent flow simulation. The model used in this study is a variant on the standard k-epsilon model called the renormalized group k-epsilon model.

\subsection{Navier-Stokes Equation}

This equation can be used for weather modeling, ocean currents, water flow in pipes and airflow around the aircraft wing. The Navier-Stokes equation in complex and simplified form can help in the design of power plants, turbines and many other things.

In terms of the inertial reference, the general form of the fluid motility equation is [9]:

$$
\rho\left(\frac{D v}{D t}\right)=-\nabla p+\nabla \cdot T+f
$$

$\mathrm{T}$ is a symmetrical tensor except when the fluid is composed of degrees of freedom that rotate like a vortex. In general, (in three dimensions) $\mathrm{T}$ has the form of the equation:

$$
T=\left(\begin{array}{lll}
\sigma_{x x} & \tau_{x y} & \tau_{x z} \\
\tau_{y x} & \sigma_{y y} & \tau_{y z} \\
\tau_{z x} & \tau_{z y} & \sigma_{z z}
\end{array}\right)
$$

Where $\sigma$ : normal stress and $\tau$ : tangential stress (shear stress)

\section{2. k- $\varepsilon$ (k-epsilon) Turbulent Model}

The most important thing to be done in the computing process is the modeling of turbulent structures in the flow field. This turbulent structure occurs at various timescales and lengths, creating a model that can analyze all these possibilities is not easily practicable. There are several different turbulence models available for turbulent flow simulation. The model used in this study is a variant on the standard k-epsilon. The k-epsilon turbulence model uses turbulent flow analysis characterized by the field of fluctuation velocity. This turbulent flow occurs due to high velocity flow and irregular movement of fluid particles, thus causing turbulence or unregulated effects. Many mixed fluctuations on the move such as momentum, energy, and concentration species have caused moving speed also to fluctuate. The K-Epsilon model adds two transport equations, which are based on $\mathrm{k}$ and $\varepsilon$ variables [9].

Equations with variable $\mathrm{k}$ ie,

$$
\rho \frac{D k}{D t}=\frac{\partial}{\partial x_{i}}\left[\left(\mu+\frac{\mu_{t}}{\sigma_{k}}\right) \frac{\partial k}{\partial x_{i}}\right]+G_{k}+G_{b}-\rho \epsilon-Y_{M}
$$

And the equation with the variable $\varepsilon$ :

$$
\frac{D \epsilon}{D t}=\frac{\partial}{\partial x_{i}}\left[\left(\mu+\frac{\mu_{t}}{\sigma_{\epsilon}}\right) \frac{\partial \epsilon}{\partial x_{i}}\right]+C_{1 \epsilon} \frac{\epsilon}{k}\left(G_{k}+C_{3 \epsilon} P_{b}\right)-C_{2 \epsilon} \rho \frac{\epsilon^{2}}{k}+S_{\epsilon}
$$

\section{Methodology}

\subsection{Turbine Archimedes Geometry}

The turbine geometry in the modeling was designed using SolidWorks software with the following dimensions (refer to reference [5]) shown in Figure 1.

After creating the geometry on Solid works, meshing process was done that divided the volume of objects into small parts by using Ansys software before the simulation held. The accuracy of the results generated through CFD calculations depends greatly on the precision of the mesh used in analyzing the flow [10]. There were a few basic meshing techniques such as a structured or unstructured mesh and the mesh can be comprised of different element types. The most common element types are hexahedra, tetrahedral, square pyramids and extruded triangles. Unstructured $3 \mathrm{D}$ grids tend to use hexahedral and tetrahedral elements, while structured grids rely more heavily on the rectangular and hexahedral elements in the simulation [11].

The process of making mesh for the test object in this research used mesh type hybrid for the volume area of the object due to the three-dimensional shape as shown in Figure 2. When using a mesh of volume with this type, the mesh formed consists mainly of tetrahedral elements, but there are also hexahedral, pyramidal, and wedge elements when we needed them. Most of the volume of objects can be directly meshed with tetrahedral / hybrid type - TGRID without having to be separated into certain volumes (it will make the number of elements more and more). 
In the use of this type the volume of objects adjacent to the volume of other objects that have been in meshshaped hex elements will result in a transition layer composed of pyramid elements. The smaller the mesh size of course results are the much better calculated. The mesh used for this study was hex dominant, with Min Size 1e-004 m, Max Face Size 1e-002, and Max Size 2e002 as shown in Figure 2.

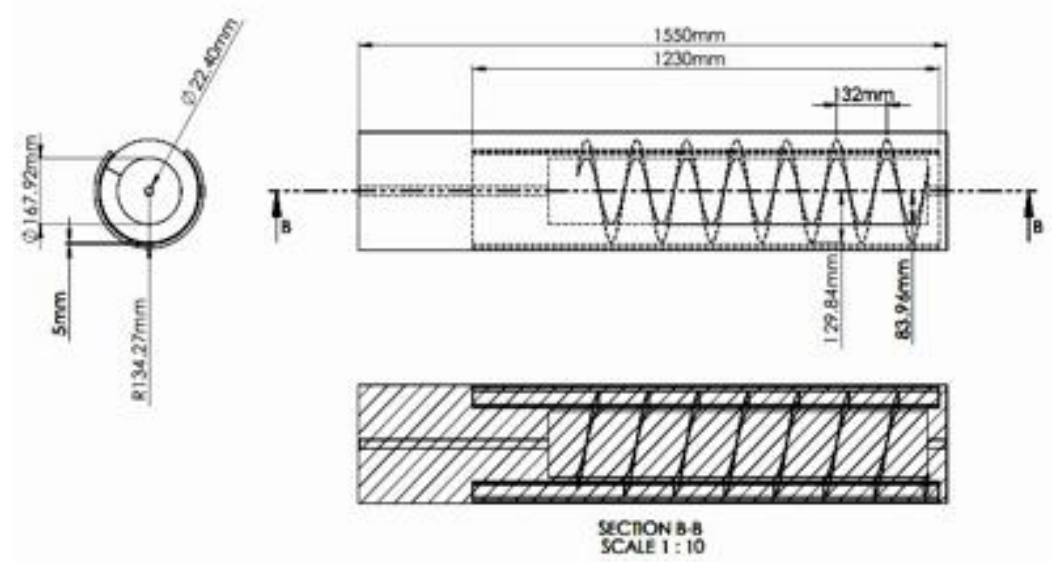
a. Turbine diameter
$=83.96 \mathrm{~mm}$
b. The outer diameter
$=129.84 \mathrm{~mm}$
c. Pitch distance
$=132 \mathrm{~mm}$
d. Turbine length
$=1230 \mathrm{~mm}$

(a)

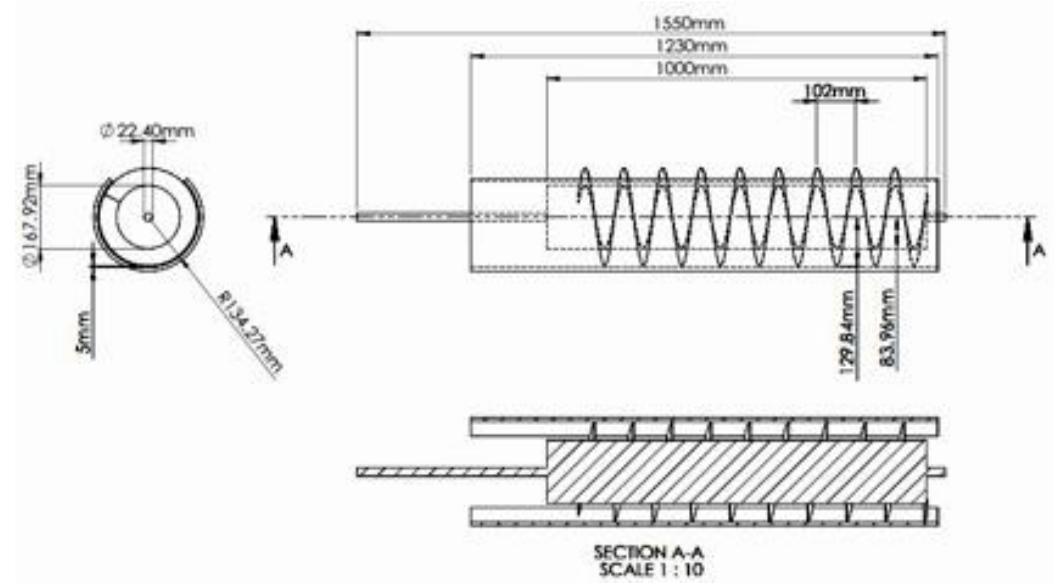
a. Turbine diameter $\quad=83.96 \mathrm{~mm}$
b. The outer diameter $=129.84 \mathrm{~mm}$
c. Pitch distance
$=102 \mathrm{~mm}$
d. Turbine length
$=1230 \mathrm{~mm}$

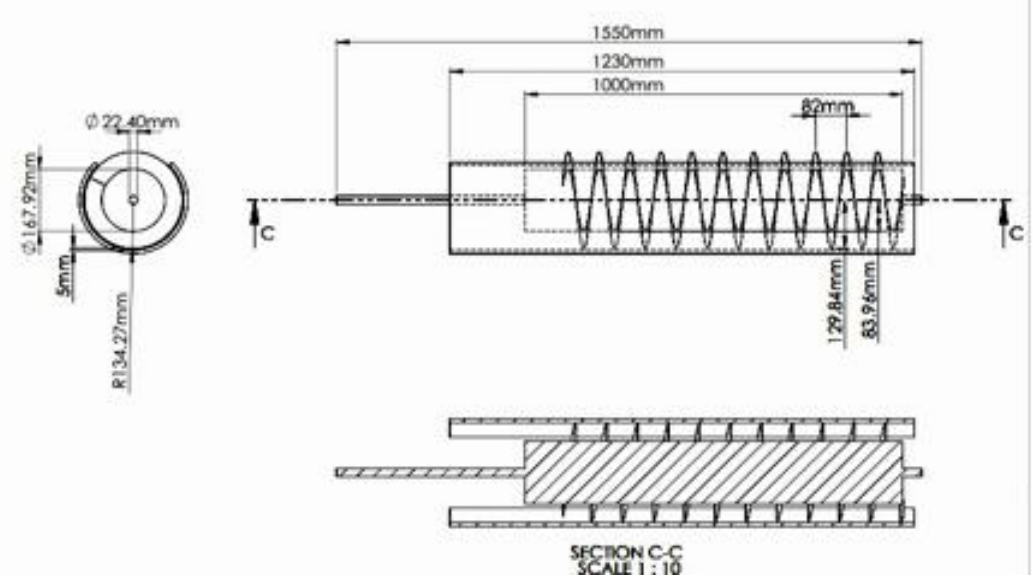
a. Turbine diameter
$=83.96 \mathrm{~mm}$
b. The outer diameter
$=129.84 \mathrm{~mm}$
c. Pitch distance
$=82 \mathrm{~mm}$
d. Turbine length
$=1230 \mathrm{~mm}$

Fig. 1. Dimensions of Archimedes Screw Turbine design 


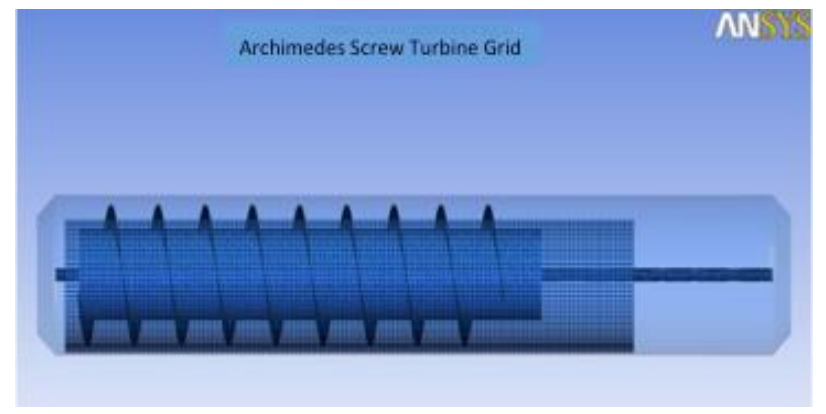

Fig. 2. Computational grid on turbine

\subsection{Input Data Parameters}

The input data used was taken based on design while the fluid physical data follows the fluid properties in the existing literature. The data are presented as shown in Table 1.

Table 1. Input data parameters

\begin{tabular}{lc}
\hline \multicolumn{1}{c}{ Properties } & Value \\
\hline Fluid Viscosity, $\square$ & $0.001003 \mathrm{~kg} / \mathrm{m} . \mathrm{s}$ \\
Fluid Density, $\rho$ & $998.2 \mathrm{~kg} / \mathrm{m}^{3}$ \\
Solid (copper) Density, $\rho$ & $8030 \mathrm{~kg} / \mathrm{m}^{3}$ \\
Inlet velocity, $V_{\text {in }}$ & $0.01579 \mathrm{~m} / \mathrm{s}$ \\
Initial Gauge Pressure, $P_{\text {in }}$ & $9810 \mathrm{~Pa}$
\end{tabular}

\section{Results and Discussion}

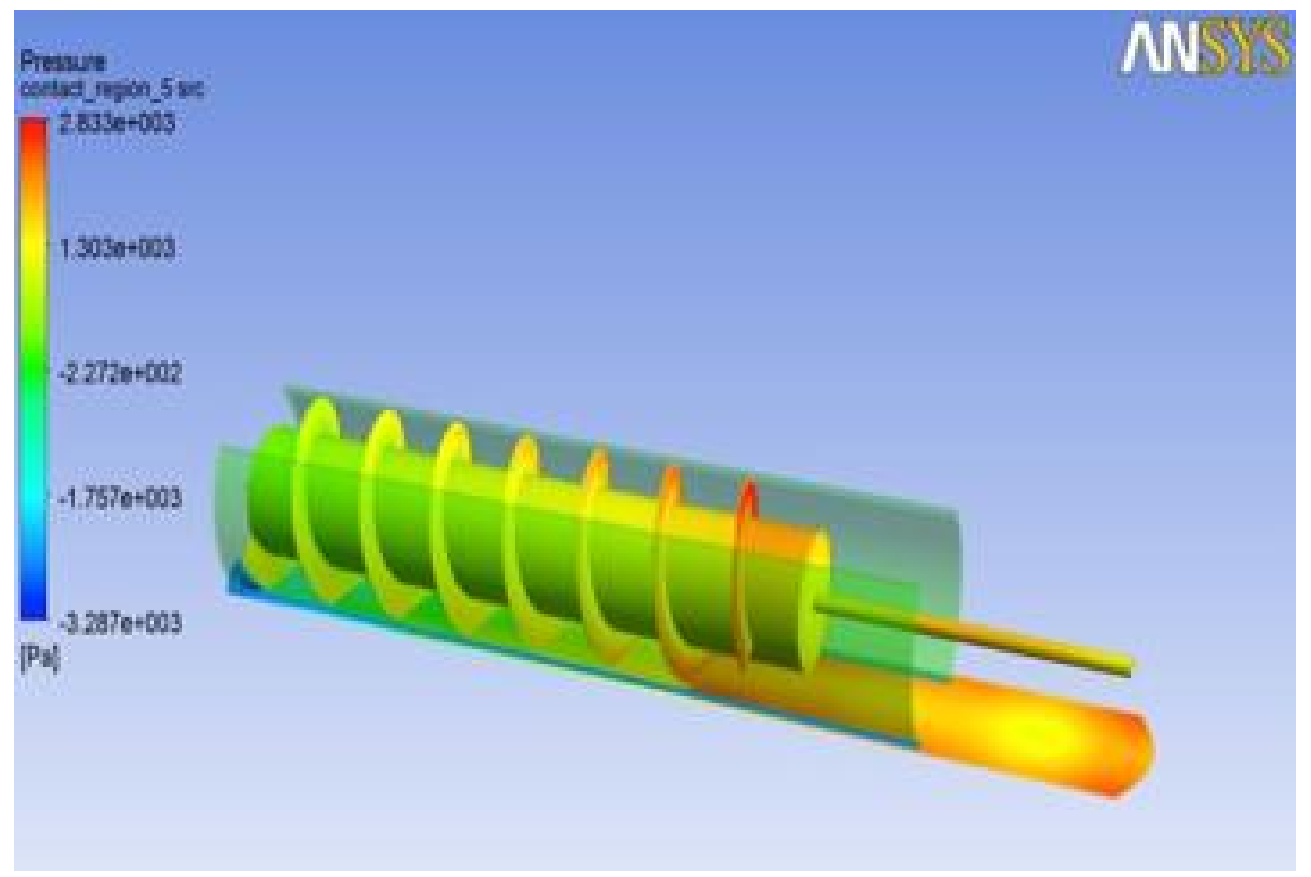

(a)

\subsection{Input Data Parameters}

To analyze numerical results, this paper presents simulation results in the form of pressure, velocity and turbulent contour kinetic energy that occurs in Archimedes screw turbines with screw number of 7, 9, and 11. By observing the difference in pressure that occurs then it can be seen the momentum changes that occur in each model of the turbine. The fluid flow velocity inside the turbine will be inversely proportional to the pressure, which then changes into the momentum that will drive the turbine.

Understand the pressure patterns that occur in the turbine blades, it can be seen the difference in performance on each turbine that is suitable for use. The greater the pressure is the greater result in shaft rotation. However, keeping in mind that the pressure will decrease as it changes into the momentum that produces a spin on the turbine shaft. In single blade turbine the pressure is still high enough at the end of the turbine output, especially when the pitch distance is small [8]. However, how optimum pitch distance may be made is examined in this study.

\subsection{Contours of velocity, pressure and turbulent kinetic energy in Archimedes screw turbines}

The Contour Pressure from the simulation results, as a function of time, can be seen in Figure 3. The corresponding velocity and turbulent kinetic energy contours generated from the interplay between turbine flow and blades are shown in Figures 4 and 5 . 


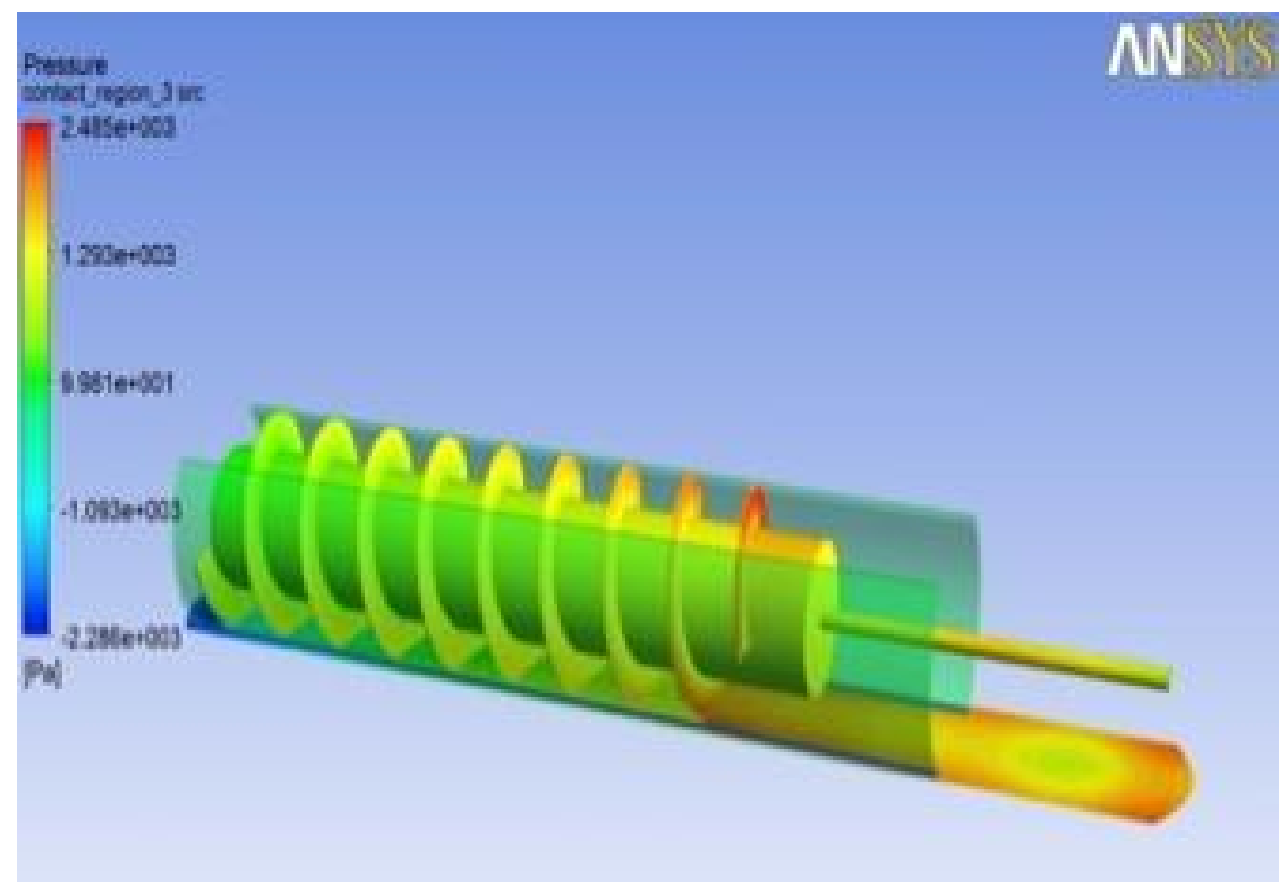

(b)

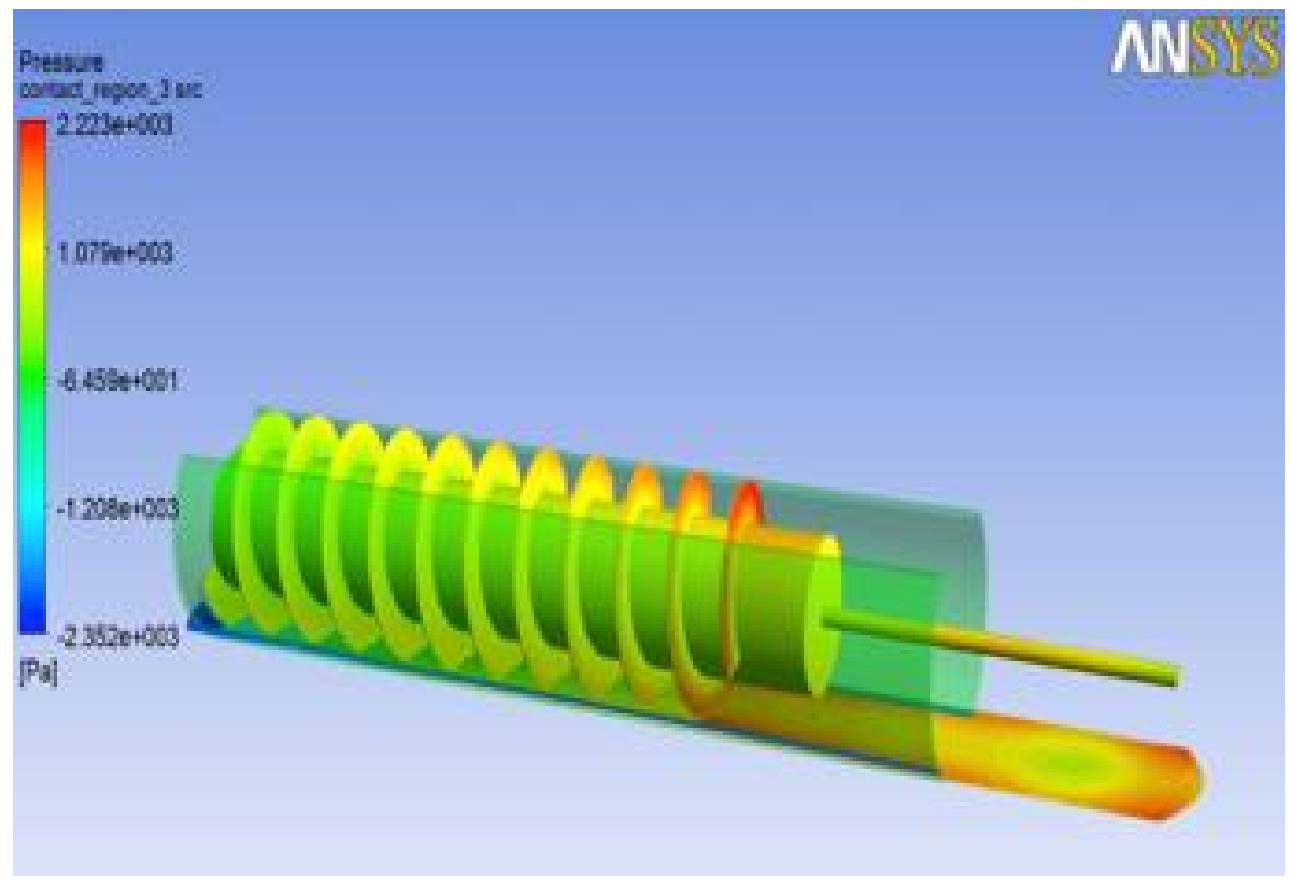

(c)

Fig. 3. Pressure Contour on, (a). 7 Screws, (b). 9 Screw, and (c). 11 Screws

Figure 3 above shows the pressure profiles that occur in turbines with an amount of 7, 9, and 11 screws. The color gradation differences that occur on the inlet and the outside of the turbine show a large pressure difference between the inlet and outlet. This condition corresponds to the basic theory of turbines, where the pressure inside the turbine changes into momentum.

A large pressure difference occurs in turbines with 7 screws, compared with 9 and 11 screw turbines. Turbines with 11 screw numbers have the lowest pressure drop. Similarly, on the inlet side of the turbine, the highest pressure occurs on a single blade turbine which has 7 screws, followed by a turbine with 9 screws and the last turbine with 11 screws. The narrow screw distance causes the speed of the passage to be high so that the amount of fluid that hit the blade wall becomes small. However, with greater pitch distance, the pressure energy on the blade will be reduced on the turbine outlet followed by an increase in flow velocity. 


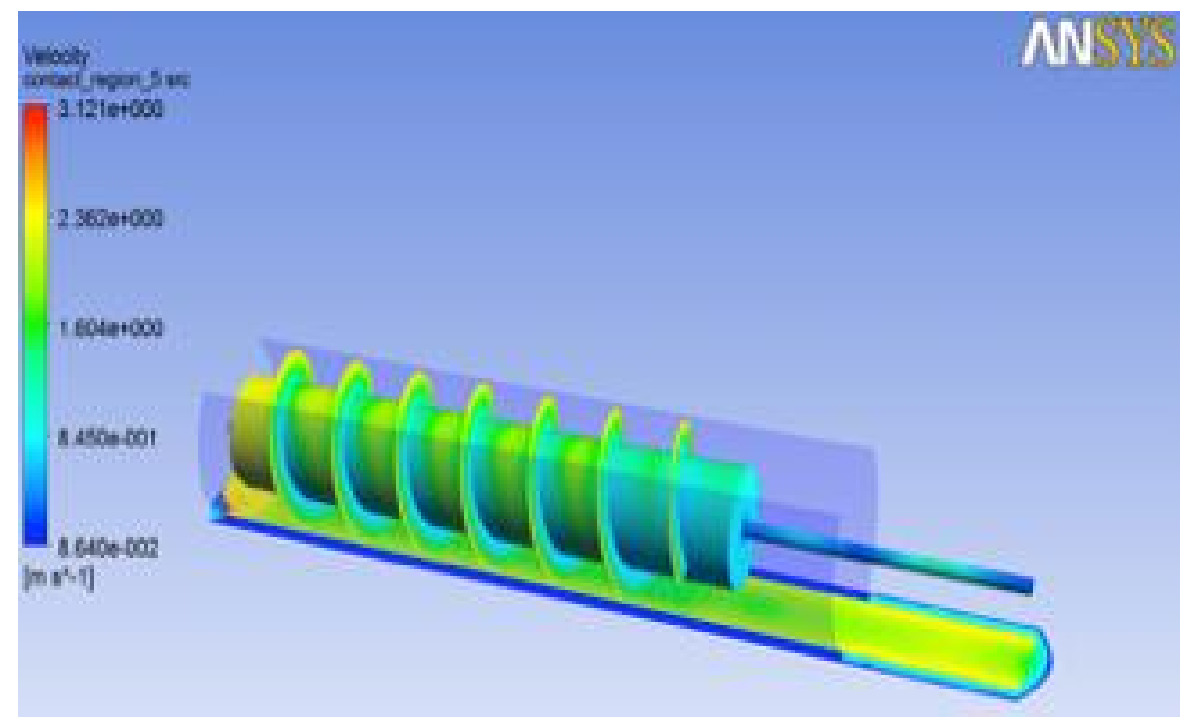

(a)

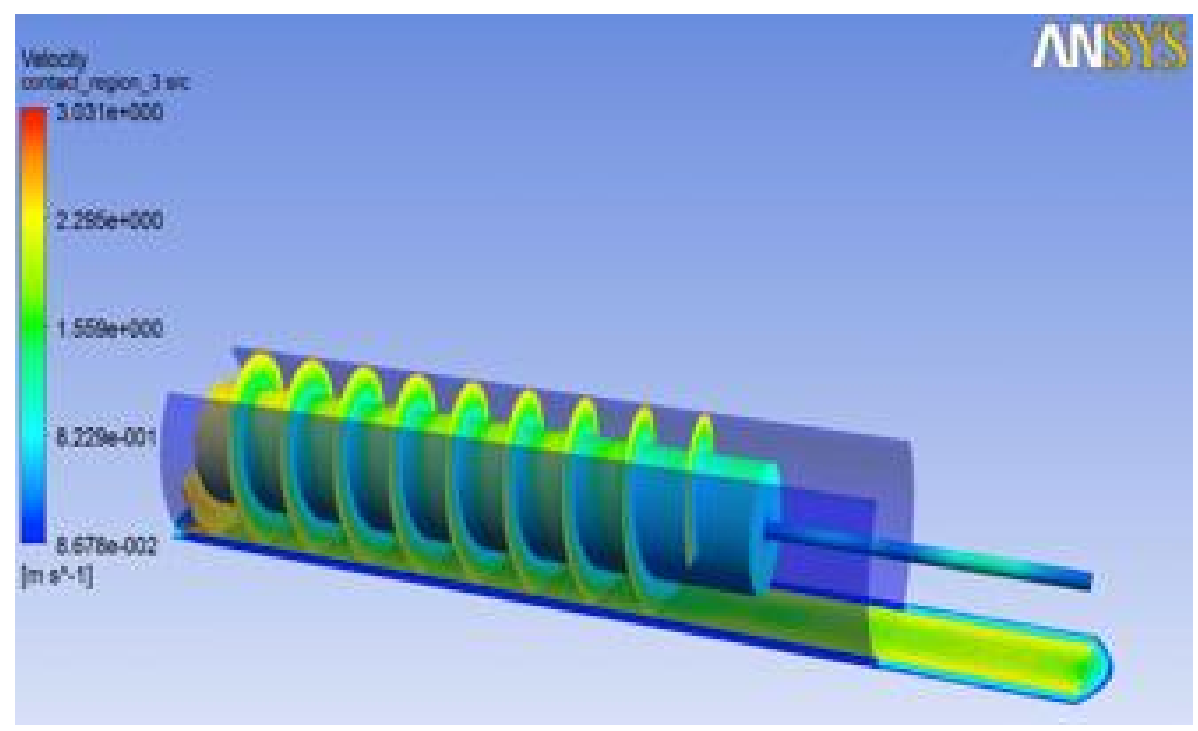

(b)

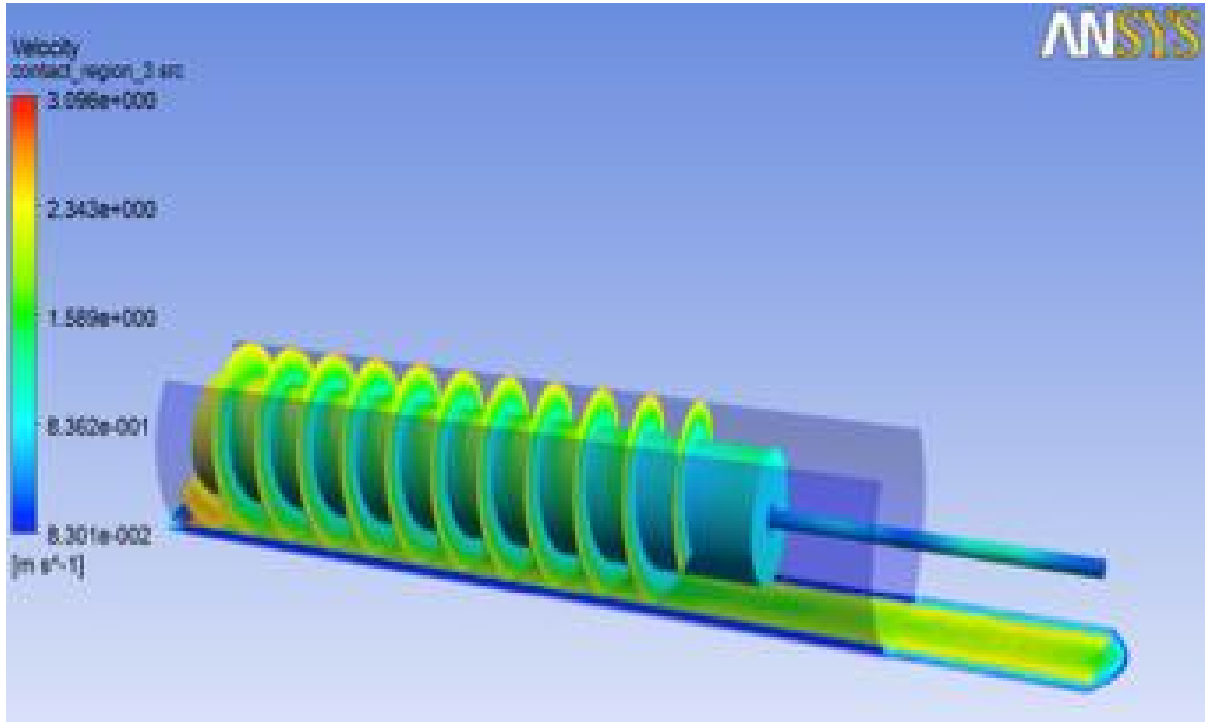

(c)

Fig. 4. Velocity Contour on (a). 7 Screws, (b). 9 Screws, (c). 11 Screws

\footnotetext{
Corresponding author: ilhammaulana@unsyiah.ac.id
} 


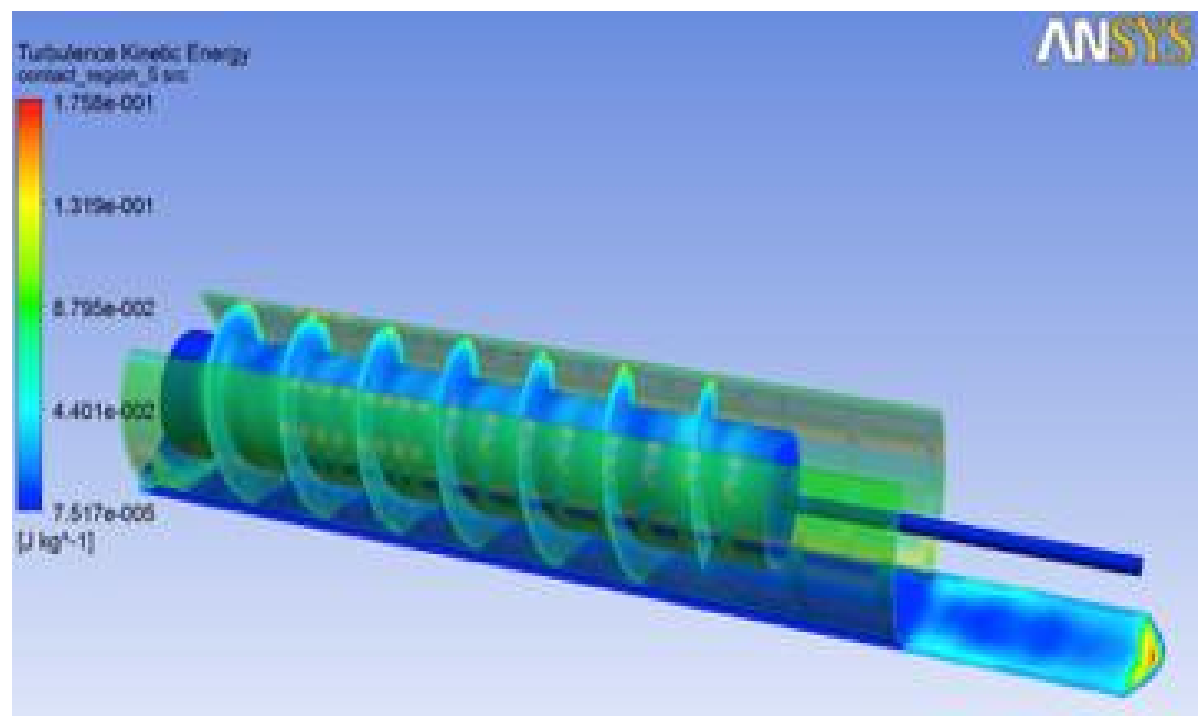

(a)

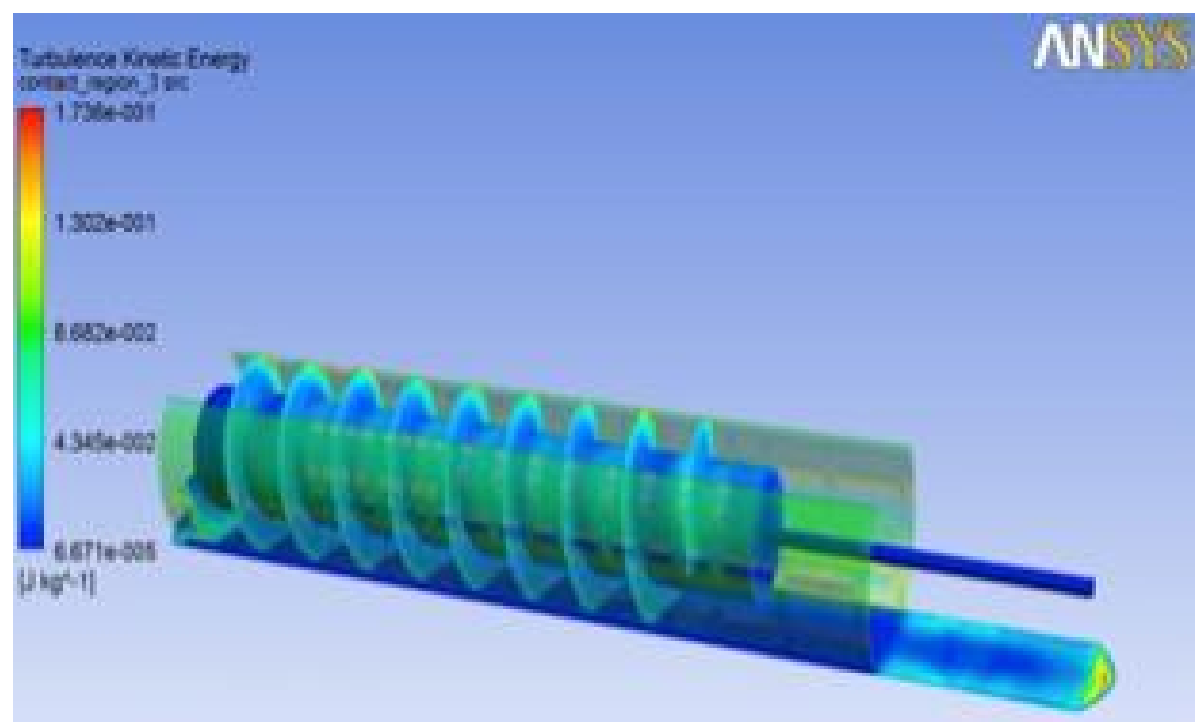

(b)

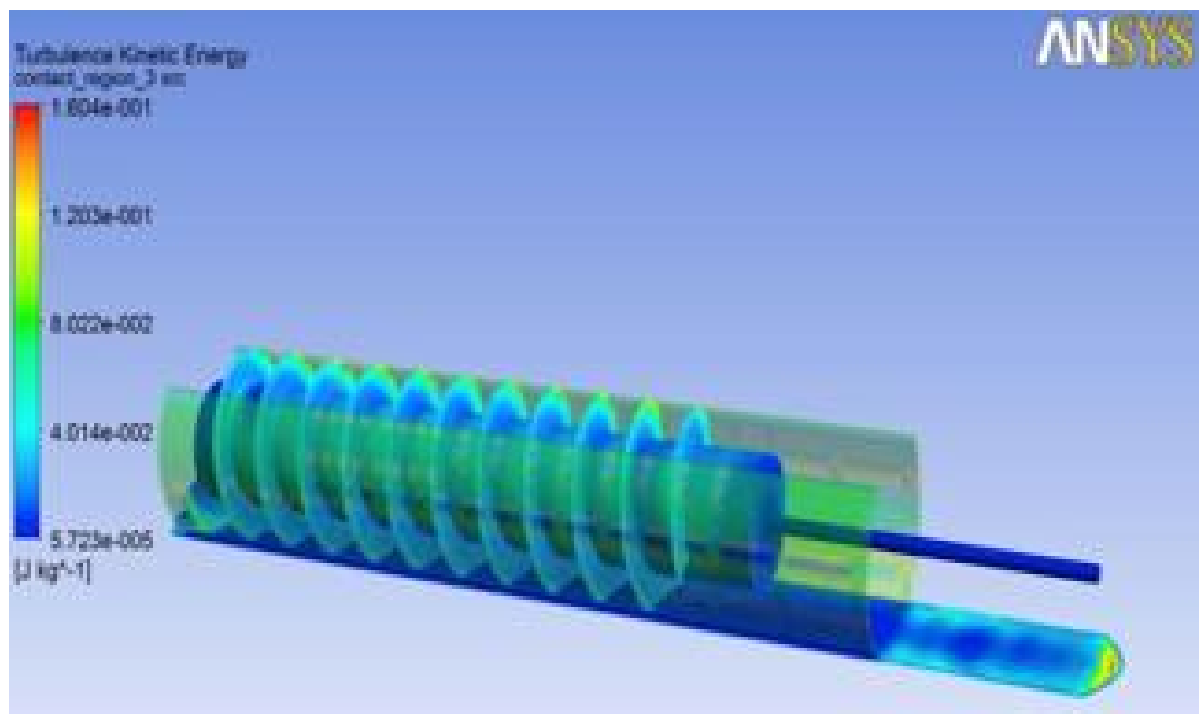

(c)

Fig. 5. Contour Turbulent Kinetic Energy on (a). 7 screw, (b). 9 screw, and (c). 11 screw numbers 
This correlation is evidenced by the flow velocity phenomenon shown in Fig. 4. (a) (b) and (c). The light blue color on the inside and the orange on the turbine outside is a sign that the speed has changed based on previous discussions where pressure occurs on the incoming side going down with increasing flow velocity. The color gradations from the turbine inlet side to the outputs at the ends of the turbines in figures 4 (a), (b) and (c) represented by orange color, indicate an increase in velocity on the outlet side of the turbine.

The phenomenon of the kinetic turbulent energy changes occurring in the turbine is shown in Fig. 5 (a) (b), and (c). This image shows the color gradation from light to the dark as a representation of the turbulent kinetic energy that occurs. At the turbine input side, the kinetic energy is higher due to the high pressure of the impact and greatly affect the momentum resulting from the pressure on turbulent kinetic energy occurring of the screw turbine Archimedes. The bright color at the top of the blade in each of the Archimedes turbines signifies a uniformly distributed kinetic energy turbulent resulting in an energy derived from the pressure of the fluid flow leading to the turbine blade.

\subsection{Characteristic Mapping of Turbine performance with different screw number}

Differences in the number of screws greatly affect the flow rate that occurs in the turbine. So, the value of pressure velocity and turbulent kinetic energy generated will also be different. This can be seen in graphs and tables as follows.

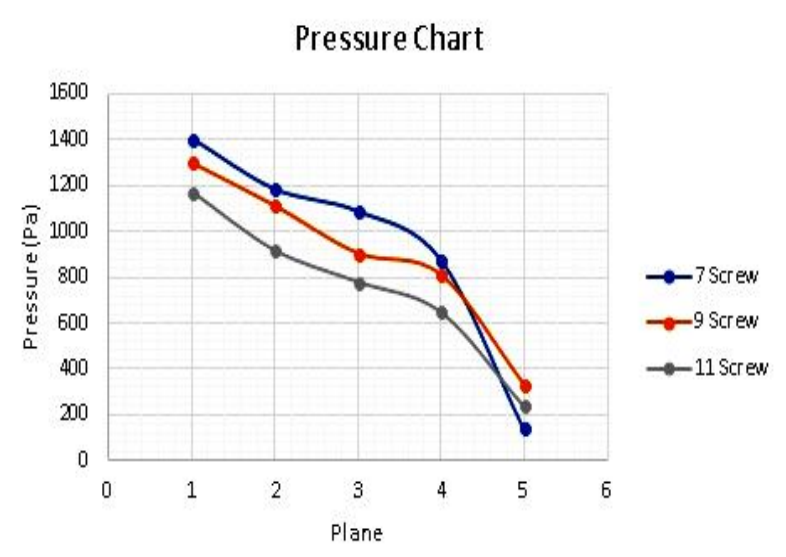

Fig 6. Pressure Distribution Chart

Figure 6 shows the graph of the mean pressure values that occur on each plane in the Archimedes screw turbine. In turbines with a total of 7, 9 and 11 screws, the graph shows a decrease in pressure on the plane 5 with values on 7 screws of 142.9 Pascal, 9 screws of 335.1 Pascal and on 11 screws 240.8 Pascal. This phenomenon corresponds to Bernoulli's law on the flow. This is due to the absence of pressure on the turbine output, because the outside pressure is the atmospheric pressure. The longer distances between the blades, resulting in the effect of free falling fluid mass more influential on the turbine with the number of 7 blades.
The real pressure values that occur in each plane is shown in Table 1. Therefore, the lowest pressure occurs on turbines that have 7 screws. This turbine has a greater flow acceleration compared to the other two types of screws number. This shows a considerable drop of pressure occurring on the turbine outlet side compared to the other two types. This phenomenon is worthy of scrutiny and further studies are needed to avoid a significant drop in pressure near the outlet of the turbine with screws of 7 pieces.

Table 1. Average Pressure Value on Archimedes Screw Turbine

\begin{tabular}{|c|c|c|c|c|c|c|}
\hline \multicolumn{7}{|c|}{ Pressure (Pa) } \\
\hline \multirow{2}{*}{ Plane } & \multicolumn{3}{|c|}{ Distance (m) } & \multirow{2}{*}{ 7 Screws } & 9 Screws & 11 Screws \\
\cline { 2 - 4 } & 7 Screws & 9 Screws & 11 Screws & & & \\
\hline 1 & 0.8132 & 0.8458 & 0.8458 & 1406 & 1301 & 1175 \\
\hline 2 & 0.6826 & 0.7478 & 0.6173 & 1185 & 1114 & 919 \\
\hline 3 & 0.5520 & 0.5357 & 0.4492 & 1088 & 906 & 781 \\
\hline 4 & 0.2811 & 0.3301 & 0.1995 & 878 & 813 & 650 \\
\hline 5 & 0.0135 & 0.0298 & 0.0298 & 143 & 335 & 241 \\
\hline
\end{tabular}

A similar trend is shown in turbines that have of 9 and 11 screws number. Therefore, in general, the pressure that occurs on the turbine has 9 units of screws higher than the turbine with 11 screws. This indicates that a small pitch distance reduces the pressure that occurs on the turbine caused by high flow velocities inside the screw.

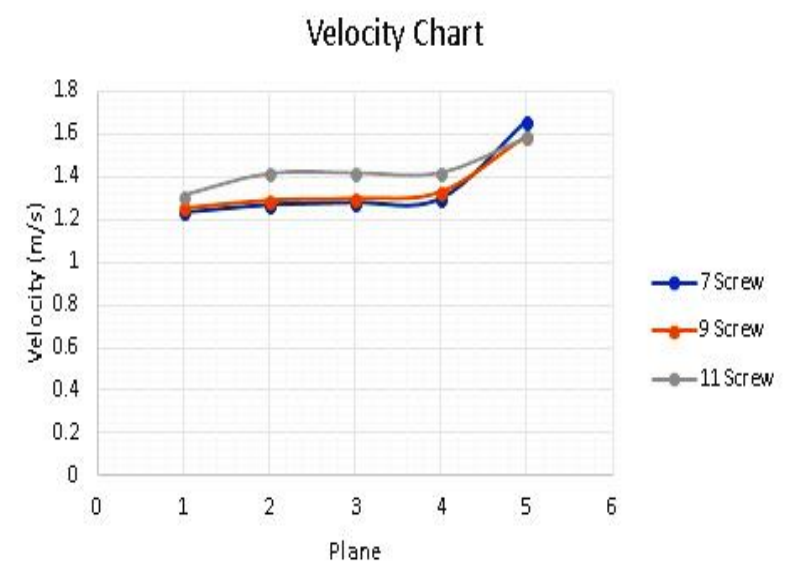

Fig. 7. Velocity Distribution Chart

The average velocity graphs in Figure 7 above shows an increase in velocity due to pressure drops on all three types of turbines. The speed increase is due to the value of pressure distributed on the turbine blade, so the pressure on the blade will decrease and change to speed. The highest speed increase occurred on plane 5, i.e. at 7 screws of $1.661 \mathrm{~m} / \mathrm{s}$, on 9 screws of $1,590 \mathrm{~m} / \mathrm{s}$, and on 11 screws of $1,586 \mathrm{~m} / \mathrm{s}$ as shown in Table 2 .

As with the phenomenon that occurs at the pressure inside the turbine, the speed increases more sharply on the turbine with 7 screws. While the other two types show a similar trend, the flow rate of turbines with 11 screws is higher than the other two types of turbine.

\footnotetext{
Corresponding author: ilhammaulana@unsyiah.ac.id
} 
Table 2. Average Velocity Values inside Archimedes Screw Turbines

\begin{tabular}{|c|c|c|c|c|c|c|}
\hline \multicolumn{7}{|c|}{ Velocity $(\mathrm{m} / \mathrm{s})$} \\
\hline \multirow{2}{*}{ Plane } & \multicolumn{7}{|c|}{ Distance (m) } & 7 Screws & 9 Screws & 11 Screws \\
\cline { 2 - 4 } & 7 Screws & 9 Screws & 11 Screws & & & \\
\hline 1 & 0.81313 & 0.845768 & 0.845768 & 1.236 & 1.255 & 1.309 \\
\hline 2 & 0.68257 & 0.747848 & 0.617288 & 1.272 & 1.292 & 1.414 \\
\hline 3 & 0.55201 & 0.535688 & 0.449192 & 1.282 & 1.301 & 1.417 \\
\hline 4 & 0.28110 & 0.330056 & 0.199496 & 1.301 & 1.330 & 1.418 \\
\hline 5 & 0.01345 & 0.029768 & 0.029768 & 1.661 & 1.590 & 1.586 \\
\hline
\end{tabular}

Figure 8 shows a graph of turbulent kinetic energy occurring inside a turbine blade. The graph shows that the turbulence that occurs in every field of blade, affecting the pressure that occurs on the wall of the turbine blade. The graph also shows turbines having 7, 9, and 11 screw units, the largest average kinetic energy turbulence value occurs on plane 2, i.e. on 7 screws of $0.1196 \mathrm{~J} / \mathrm{kg}$, on 9 screws is $12,31 \mathrm{~J} / \mathrm{kg}$ and on 11 screws that is equal to $19.03 \mathrm{~J} / \mathrm{kg}$. The actual kinetic energy turbulent values for each type on the whole plane are shown in Table 3 below.

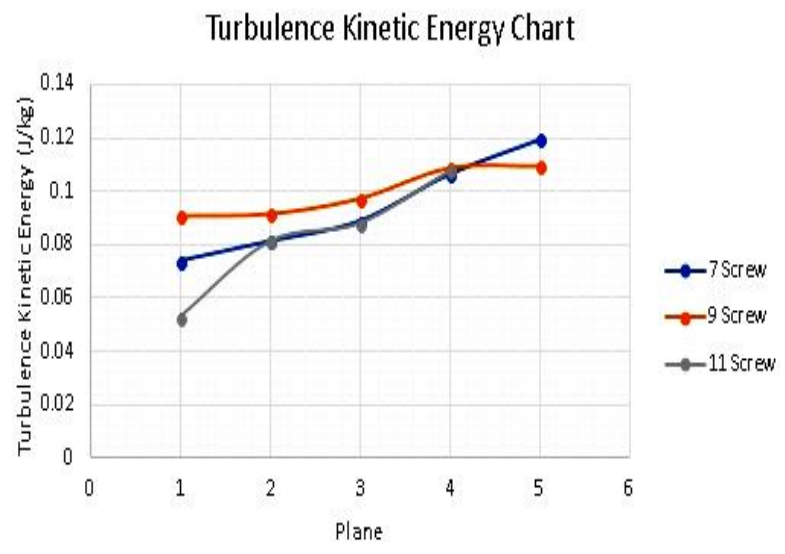

Fig. 8. Turbulent Kinetic Energy Chart

Table 3. Value of Average Turbulent Kinetic Energy in Archimedes Screw Turbine

\begin{tabular}{|c|c|c|c|c|c|c|}
\hline \multicolumn{7}{|c|}{ Kinetic Energy Turbulent $(\mathrm{J} / \mathrm{kg})$} \\
\hline \multirow{2}{*}{ Plane } & \multicolumn{3}{|c|}{ Jarak (m) } & \multirow{2}{*}{7 Screws } & \multirow{2}{*}{9 Screws } & \multirow{2}{*}{11 Screv } \\
\hline & 7 Screws & 9 Screws & 11 Screws & & & \\
\hline 1 & 0.813128 & 0.845768 & 0.845768 & 0.1065 & 0.1085 & 0.1076 \\
\hline 2 & 0.682568 & 0.747848 & 0.617288 & 0.1196 & 0.1093 & 0.1107 \\
\hline 3 & 0.552008 & 0.535688 & 0.449192 & 0.08873 & 0.09736 & 0.08802 \\
\hline 4 & 0.281096 & 0.330056 & 0.199496 & 0.08107 & 0.09178 & 0.08119 \\
\hline 5 & 0.013448 & 0.029768 & \begin{tabular}{|l|}
0.029768 \\
\end{tabular} & 0.07365 & 0.09105 & 0.05283 \\
\hline
\end{tabular}

But on the next plane turbulent kinetic energy decreased the value that is not too large on the turbine with the number of screws 9 pieces. This condition indicates that no significant changes in turbulence flow in this turbine. Turbines with 7 pieces of screws have the highest mean value of turbulent kinetic energy, while turbines with 11 screws have the lowest average value of turbulent kinetic energy.
Based on the three flow phenomena above, the Archimedes turbine with 7 pieces of screws has the best performance among the three turbine types as it has the highest-pressure pattern and high turbulent kinetic energy value. Archimedes turbine with 9 pieces of screws has slightly lowered performance while a turbine with 11 pieces of screws has the lowest performance among the three turbine types. This suggests that proper selection of pitch distances is critical in designing an Archimedes screw turbine as described under flow conditions that occur within the turbines.

\section{Conclusion}

Based on the simulation results using CFDs against flow patterns in the single blade Archimedes screw turbine, it can be concluded:

1. The results of CFD analysis in the form of turbulent kinetic pressure, velocity and energy, they show that turbine performance using 7 screws is better than other types, followed by turbines with 9 screws and 11 screws.

2. The pressure is inversely proportional to the flow velocity inside the blade. With maximum value near the inlet side for a turbine with 7 screws is $1301 \mathrm{~Pa}$ and outlet turbine is $142,9 \mathrm{~Pa}$. The maximum value on the inlet side for turbine with 9 screws is $1406 \mathrm{~Pa}$ and at the outlet is $335.1 \mathrm{~Pa}$. And the maximum value on the inlet side for the turbine with 11 screws is $1175 \mathrm{~Pa}$ and the outlet side is $240.8 \mathrm{~Pa}$.

3. Based on the analysis, if the distance between the turbine blade is smaller, the flow velocity will increase, so that the pressure in the inlet position all directly leads to the tip of the blade and produces a low momentum.

Acknowledgments submitted to the Directorate of Research and Community Service Directorate General Strengthening Research and Development Kemenristek Dikti through Institute for Research and Community Service Syiah Kuala University that has provided support through research programs scheme of Primary Research of Higher Education.

\section{References}

1. Akhilesh Arvin Nimje., and Gopal Dhanjode, Pico - Hydro - Plant for Small Scale Power Generation In Remote Village, IOSR Journal of Enviromental Science, Toxicology and Food Technology (IOSR - JESTFT) e - ISSN: 2319 - 2399, Issue 1 ver. III, PP 59-67, India (2015)

2. Rorres C. The turnoff the screw: Optimal design of the Archimedean screw. Journal of Hydraulic. 126(1): 72-0 (2000).

3. Muller G and Senior J. Simplified theory of Archimedean screws. J of Hydraulic Research; 47(5): 666-69 (2009).

4. Dellinger G, Terfous A, Garambois PA, Ghenaim A. Experimental investigation and performance 
analysis of Archimedes screw generator. J of Hydraulic Research:1-13 (2016).

5. Lubitz, W. D., Lyons, M., and Simmons, S., Performance Model of Archimedes Screw Hydro Turbines with Variable Fill Level. Journal of Hydraulic Engineering, 140(10), 04014050 (2014).

6. Stergiopoulou, A., Stergiopoulos V., and Kalkani, E., An eagle's CFD view of Studying Innovative Archimedean Screw Renewable Hydraulic Energy System, Proceedings of the 4th International Conference on Enviromental Management, Engineering, Planning and Economics (CEMEPE) and SECOTOX Conference, ISBN: 978-960-686568-8, Mykonos island, Grecee (2013).

7. MAN Mutasim, NS Azahari, AAA Adam, Prediction of Particle Impact on an Archimedes Screw Runner Blade for Micro Hydro Turbine, Applied Mechanics and Materials 465, 552-556, (2014).

8. MI Maulana, A Syuhada, M Nawawi, Blade number impact on pressure and performance of archimedes screw turbine using CFD, AIP Conference Proceedings 1931 (1), 030037, (2018).

9. Fluent Inc.'s., FLUENT 5 User's Guide Volume 2, Fluent incorporated, Lebannon, (1998).

10. F. Frunzulica, I. C. Andrei, L. Sikolya and E. Korody, "Special Aspects in Triangulation and Mapped Meshing," Fascicle Mechanics, Tribology, Machine Manufacturing Technology, Baia Mare, (2005).

11. J. P. Steinbrenner and J. R. Chawner, "Gridgen's Implementation of Partial Differential Equation Based Structured Grid Generation Methods," In Proceding of the $8^{\text {th }}$ International Meshing Rountable, South Lake Tahoe, (1999). 